\title{
AC 2012-3810: UNIVERSITY STUDIES OF STUDENT PERSISTENCE IN ENGINEERING
}

\author{
Dr. Gretchen L. Hein, Michigan Technological University \\ Mrs. Kaitlyn J. Bunker \\ Dr. Nilufer Onder, Michigan Technological University
}

Nilufer Onder is an Associate Professor of computer science at Michigan Technological University. She received her Ph.D. in computer science from the University of Pittsburgh. Her research areas are artificial intelligence planning systems and decision making under uncertainty. Her webpage can be found via http://www.cs.mtu.edu/.

Miss Raven Rachaun Rebb

Dr. Laura E. Brown, Michigan Technological University

Dr. Leonard J. Bohmann, Michigan Technological University

Leonard J. Bohmann received his B.S. in electrical engineering from the University of Dayton in 1983, and his M.S. and Ph.D. in electrical engineering from the University of Wisconsin in 1986 and 1989, respectively. After graduating, he accepted a faculty position at Michigan Tech in the Department of Electrical and Computer Engineering. Bohmann was appointed interim chair of the Department for the 2007-08 academic year, and, in 2007, he was also appointed to his present position of Associate Dean for Academic Affairs within the College of Engineering. He is an ASEE member and participates in the Electrical and Computer Engineering, Energy Conversion and Conservation, Computers in Education, and Educational Research and Methods divisions. He is the past Chair of the Electrical and Computer Engineering Division. 


\title{
UNIVERSITY STUDIES OF STUDENT PERSISTENCE IN ENGINEERING AND COMPUTER SCIENCE
}

\begin{abstract}
In Spring 2011, engineering and computer science students at Michigan Technological University were surveyed with respect to persistence in their major. The survey was designed to investigate the aspects of persistence and the reasons behind switching majors. This paper extends the analysis to include two independent studies that were conducted in 2009. The studies were academic surveys of climate and persistence with the intent of providing university benchmarks for improvement. The three surveys overlap on questions regarding perception of professors (within the classroom and their personal treatment of students), perception of treatment with respect to gender, the contacts and interactions with fellow students, and the students' perceptions of the field of engineering. The three data sets were analyzed individually and collectively to determine what impacts student persistence (including factors such as major, gender, student-student and student-faculty interactions, and career opportunities). Our analysis revealed agreement among the three surveys on topics related to persistence. We found significant gender differences were not prevalent, but when they occurred they were consistently found in multiple instruments.
\end{abstract}

\section{Introduction}

The US economy as well as the global economy increasingly relies on a workforce that is highly educated in engineering and computer science. Even though careers in these disciplines usually promise a job that is well-respected by the society along with a good salary, the number of engineering and computer science graduates are well below the national need ${ }^{4,16}$. Moreover, the percentage of females in many engineering and computer science programs has been consistently low for several decades ${ }^{17}$. As a result, the study of persistence of students in engineering and computer science disciplines is of widespread interest to researchers.

Research literature in this topic includes a wide range of studies that vary greatly in size, ranging from surveys that cover a single institution to surveys that cover hundreds of institutions and several tens of thousands of students, e.g., National Survey of Student Engagement (NSSE) and Project to Assess Climate in Engineering (PACE) $)^{1,18,20}$. The surveys vary in their focus, ranging from gender issues in a single department to the aspects of student engagement. On one hand, studies that have a more general focus and reach many students have the advantage of collecting a more representative sample, but these surveys cannot go into depth on a specific topic because the survey instrument becomes too long. On the other hand, more focused studies have the advantage of comprehensively covering the issues on a specific topic or an institution, but their sample size is usually limited.

In this paper, we bring together and analyze a small-scale, single institution survey on student persistence; and two large-scale, multi-institute surveys on student persistence, climate, and engagement. First, a brief review of the relevant literature is presented. Then, we describe the 
survey instruments and analyze the results from these surveys on a multitude of aspects regarding persistence. We conclude with a summary, recommendations, and future work.

\section{Background and Related Work}

The issues surrounding why students choose to persist within a given major or switch to another are complex. The factors that affect student decisions can be broadly classified into three groups as (a) academic resources, (b) internalization and perceptions of the major and career, and (c) climate and experiential effects. The academic resources include lectures, recitations, and laboratories; faculty and teaching assistants; university services such as advisors and career placement; and academic services such as study centers and academic progress monitoring. Internalization refers to perceptions of the self including confidence, self-efficacy, and determination to succeed. Perceptions of the major and career include students' interest in choosing and retaining engineering as a major and a career, the opportunities and advancements provided by the field to the society, and the society's perception of the field. Climate and experiential effects involve personal experiences such as stereotypes and the university environment. In the following sections, we briefly review samples of research in each of the three groups.

\section{II.a. Academic Resources}

Universities strive to provide an excellent education by providing a wide variety of academic resources that are accessible to all of their students. A prior study showed that students who persist in engineering have more awareness of support services such as academic advisors, engineering student organizations, faculty, and tutors than those who switch majors. Students who persist are also more likely to use these services, and to find them helpful ${ }^{9}$.

Prior work analyzes the usage and effectiveness of these resources based on student characteristics such as persistence and gender. Survey data from the Multiple-Institution Database for Investigating Engineering Development (MIDFIELD) and the National Survey of Student Engagement (NSSE) were analyzed to compare students who persist in engineering to those who leave. This research found that engineering students persist within their major at rates higher than any other major. The demographics of engineering students are similar to other majors, except for the low percentage of women. Engineering students perceive that their grades are lower than other majors, but the survey data show that engineering students' academic performance is similar to other majors. Engineering students are engaged within their classrooms, and with faculty and other students at the same level as other majors. All students, regardless of their major, become less engaged as they progress through their degree program. Students who switch majors tend to disengage earlier than persisters ${ }^{19}$.

Litzler and Young used latent class analysis on the PACE data collected in 2008 to identify three classes of students: (1) committed, (2) committed with ambivalence, and (3) at-risk of attrition. Their analysis shows that as GPA increases, respondents are less likely to be in the "committed with ambivalence" and "at-risk of attrition" groups. However, an extended model shows the opposite: among similar levels of student experience variables such as confidence and student interaction, individuals with lower GPA are more likely to be in the "committed" group. These results confirm that GPA is not an indicator of persistence when used in isolation ${ }^{12}$. 
Hartman and Hartman performed a longitudinal study at Rowan University's engineering program $^{7}$. They found that non-persisters are less satisfied than persisters with the opportunities the program offers and the choices within the program. However, levels of satisfaction with course workload, laboratory work, and faculty-student relationships were similar between persisters and non-persisters. The gender-based analysis showed that non-persisting female students have higher mathematics scores compared to persisters. Moreover, female leavers did not have the same low grades as male leavers. These results suggest that female students have the academic ability to complete an engineering degree, but not the interest ${ }^{7}$.

Mendez et al.'s research showed that gender is not an important factor in persistence. Their analysis showed that rates of persistence are similar within subgroups of the data defined by cumulative GPA and number of STEM courses taken. In other words, once women decide to major in a STEM field, they persist at the same rate as $\operatorname{men}^{14}$.

\section{II.b. Internalization and Perceptions of Major and Career}

Students are affected in varying degrees by outside influences. Several researchers have been investigating these effects and influences over many years. Some of their findings are summarized below.

In 1993, research showed that for all engineering students who persisted, academic performance was the overall predictor of persistence, regardless of gender. When the data were separated by gender, the top predictors were different. Expected salary was the top predictor for women, but was not one of the top factors for men. Job security was more important for students who persisted within their major than for the non-persisters ${ }^{9}$. On a related note, first-year students who switched from engineering reported more frequently that the job opportunities in engineering were lacking 5 .

When students were asked about work-life balance, women expected more career delays for child rearing than men. Also, men who persisted within their engineering degree program reported expecting to also delay their careers for child rearing more than non-persisting males ${ }^{9}$.

Engineering students who persisted within their major reported that they viewed "making a difference" as more important than the students who did not persist ${ }^{9}$. This finding is not unexpected. Other researchers have shown that persisters state that engineering is a wellrespected discipline and one where they can make a positive impact ${ }^{5}$. Non-persisters did not have this same perception of the discipline.

Burtner found that a student's confidence in their study habits can have an effect on their persistence in engineering ${ }^{5}$. Another study showed that a student's self-confidence has an effect on their persistence, and that self-confidence tends to decrease as a student moves through their degree program ${ }^{2}$. In the same study, it was found that low self-confidence was the most highly ranked factor that prevented persistence for women students. This lack of self-confidence became more of a barrier to persistence as the women students progressed further into their majors. Non-persisting engineering students reported that they have less confidence in their study skills than those students who persist ${ }^{5}$. Another study showed that some students persist 
out of doggedness (a strong determination to complete their degree) regardless of their confidence, level of enjoyment, or satisfaction ${ }^{13}$.

The academic background that students receive from their high school education has an effect on their persistence in engineering. Jackson et al. showed that there were no differences in high school GPA, ACT or SAT scores, or family background between students who persist than those who switch majors. However, the results also showed a difference between men and women students with respect to their academic background. Women students tended to rank themselves as having lower academic ability in science, math, and writing compared to other high school students ${ }^{9}$.

In 2009, Pierrako et al. completed focus groups and individual interviews with 8 first-year engineering students (equally distributed between persisters and non-persisters and by gender). The research found that students who entered engineering with more exposure to engineering in high school (through coursework, knowing an engineer, in-depth engineering exposures, engineering competitions) were more likely to continue their engineering studies than students with less exposure ${ }^{21}$.

\section{II.c. Climate and Experiential Effects}

Although all students complete core, discipline-specific courses, their personal perceptions of these experiences influence their decisions. Students' academic performance affects their perception of if and when they will complete a degree program. Their performance also colors their view of their department, courses and university. Additionally, this perception can affect how long they believe they will be in a given career field. The literature shows that men and women differ greatly in this area.

In one study, most of the engineering students chose their major because they saw themselves as good at math, regardless of whether they ended up persisting or not. Students who switched majors were encouraged by counselors, parents and friends to "try" engineering without much knowledge of the field. The persisters found ways of connecting with their peers and the faculty, while the students who switched majors did not. The leavers were less likely to participate in engineering activities and clubs at the university than persisters ${ }^{21}$.

A study of approximately 300 science, math and engineering students was completed to investigate commitment to their major based on intention to stay in current major, attain their degree, and long-term commitment to being a scientist or engineer. The independent variables were what are the students' images of scientists/engineers, the perceptions of gender equality in these fields, and how gender and race affect the classroom environment. The study found that the probability of women students completing their degree was half that of men. "Women were $38 \%$ less likely to see themselves as scientists or engineers in 20 years." Overall, the students, regardless of gender, had a positive attitude of gender equality within their major and society with women being more sensitive than men to the classroom environment ${ }^{22}$.

\section{III.Methodology}

Three studies on student persistence, climate, and engagement were compared. The small-scale, single institution persistence survey was designed to investigate aspects of persistence and the reasons behind switching majors at Michigan Technological University (Michigan Tech). A 
large-scale, multi-institute survey was the multi-site Project to Assess Climate in Engineering (PACE $)^{1,20}$. This long-term study looks at climate with a focus on persistence and retention using both a quantitative survey and qualitative interviews and focus groups; only the survey results will be used in this paper. An engagement survey was designed to investigate the deployment and use of educational resources by students and universities and was conducted by the National Survey of Student Engagement (NSSE) institute ${ }^{18}$. Michigan Tech participated in all three studies; the results presented below concern only Michigan Tech respondents.

Michigan Tech is a Science, Technology, Engineering, and Mathematics (STEM)-intensive, public university, located in the midwest region of the U.S. The university has an undergraduate enrollment of approximately 5500 students with $60 \%$ enrolled in either engineering or computer science (Eng\&CS) degree programs. The university has $28.7 \%$ female enrollment with the Eng\&CS programs having $18.2 \%$ female enrollment.

The authors' persistence survey was conducted in February 2011 as an anonymous, online survey $^{3}$. Invitations to participate in the study were sent to all students in the Eng\&CS programs by the student's respective program advisors; additional reminders were sent to female faculty to remind their classes and campus societies to increase participation. After excluding nonengineering or computer science majors, graduate students, and those who did not complete the survey, the study population was 436 students (13.4\% response rate). Several questions relating to who or what factors influenced choice of major, persistence in a major, switching of a major were asked with 5-point Likert scale responses recorded. A $\chi^{2}$ test was run (on condensed responses) to determine if the survey responses were independent of gender at the $p \leq 0.05$ level.

The PACE survey was performed online in 2009 for students at 22 different institutions. Invitations to participate were sent using stratified random sampling, with women and underrepresented minority students intentionally oversampled ${ }^{1}$. Over 10,000 students completed the survey. Michigan Tech had 1,034 Engineering students invited to take the survey with 493 completing the survey. The student responses to the 5-point Likert questions focused on instruction, professors, resources, perceptions, major, confidence and personal experience (those topics with related question in the other two studies) were used for comparisons. The PACE team performed t-tests to determine which items had statistically significant differences between male and female students ( $\mathrm{p} \leq 0.05$ level). For comparison to our persistence survey, only data from Michigan Tech students are used in this study.

The NSSE study is a national, longitudinal survey with almost 1,400 institutions participating since its initiation ${ }^{18}$. The NSSE survey studied from 2009 included 640 institutions. Each institution performed either random or censored sampling of first-year and senior students in all majors to complete the survey (both paper and Web-based versions were available). Michigan Tech had 674 engineering students complete the survey. The NSSE questions have 4,7 or 8point ordinal or yes/no responses. A $\chi^{2}$ test was used determine if the survey responses were independent of gender at the $\mathrm{p} \leq 0.05$ level. Questions related to academic and intellectual experiences and quality of relationships were used for comparisons. Again, for comparison purposes, only data from Michigan Tech students are used here. More details of the three studies and the statistical analysis can be found at each respective publication ${ }^{3,1,18}$. 


\section{Survey Findings and Discussion}

The following section compares the results from the persistence survey, the PACE study and the NSSE data with respect to university resources, how students perceive they are affected by outside influences, and their perceptions of the campus climate. The results for questions related to Academic Resources, Internalization and Perceptions of the Major and Career, and Climate and Experiential Effects are summarized in Tables 1 through 3, respectively. These tables only present the PACE and NSSE survey results in condensed form (to help preserve Michigan's Tech anonymity and not divulge protected information, as well as making the tables easier to read). In all three tables, the means for our survey results and for the PACE results are based on a scale of 1-5. The means for the NSSE results are based on the scale shown for each question.

\section{IV.a. Academic Resources}

According to the PACE survey, the actual GPAs of Michigan Tech female and male students were similar with mean values of 3.3 and 3.2, respectively. In our small-scale persistence survey, the students were asked to rate the importance of "I have a good GPA in my major" in persisting within their major. The percentage of male and female students who rated this factor as important were similar at $46.3 \%$ and $45.3 \%$, respectively. However, the percentage of female students who rated this factor as moderately important was significantly higher at $36.5 \%$ as compared to $26.7 \%$ for male students ${ }^{3}$. This observation is consistent with prior research reporting that female students are as successful academically as male students but put a slightly higher emphasis on their grades when assessing their performance ${ }^{11,15}$. Table 1 summarizes the results of this section, presenting the data from the persistence survey, the PACE study, and the NSSE study for the questions related to academic resources.

The Eng\&CS programs maintain several learning centers where students can study at any time, and can ask questions to upperclassman coaches during scheduled open coaching hours. Learning centers are available in Chem. Eng., Civil and Environ. Eng., Elec. and Comp. Eng., First-Year Eng., Materials Science and Eng., and Mech. Eng. When asked in the PACE study whether the study centers in the College of Engineering are useful (scale of 1: not at all - 5: extremely), the responses were significantly different by gender. Male students rated this resource as useful with a mean of 3.4, while female students responded with a mean of $3.1^{1}$.

The PACE study did not find that Michigan Tech students had statistically significant gender differences on the factors of quality of teaching, professors, teaching assistants, labs, and resources. Though not statistically different, there were notable differences with respect to professors. When asked about being "comfortable meeting with professors for academic help" the mean values were the same for both genders (3.9) but more male students $(76.0 \%)$ answered "usually" or "all the time" compared to female students (70.9\%). When asked if "professors inspire you to study engineering" the mean values were the same for both genders (3.6) but more male students $(55.2 \%)$ answered "usually" or "all the time" compared to female students (51.9\%). For "meet with your professors for extra help", the mean value was slightly higher for female students (3.0) compared to male students (2.8) and more female students $(26.0 \%)$ answered "usually" or "all the time" compared to male students $(19.1 \%)^{1}$.

The PACE data showed small gender differences with respect to academic services. The mean values of responses to "advisors in COE helpful" were the same at 3.7, but more female students 
$(23.0 \%)$ rated the advisors as being extremely helpful compared to male students $(15.3 \%)$. With respect to "satisfied with COE job placement help", the mean values were similar at 3.7 for female students and 3.8 for male students in this question" ${ }^{1}$.

Table 1: Results of Three Surveys for Academic Resources

\begin{tabular}{|l|l|ccc|cc|}
\hline & & \multicolumn{4}{|c|}{ Percentage of Respondents (\%) } & \multicolumn{2}{c|}{} \\
MTU Survey statement & Gender & Unimportant & Neutral & Important & Mean & Sig. \\
\hline Why did you persist? & $\mathrm{F}$ & 18.2 & 36.5 & 45.3 & 3.39 & $*$ \\
"I have a good GPA" & $\mathrm{M}$ & 27.0 & 26.7 & 46.3 & 3.26 & \\
\hline
\end{tabular}

\begin{tabular}{|c|c|c|c|}
\hline PACE question & $\begin{array}{l}\text { Mean } \\
\text { F }\end{array}$ & $\begin{array}{c}\text { Mean } \\
\text { M }\end{array}$ & Sig. \\
\hline "study centers in COE are useful" & 3.1 & 3.4 & $*$ \\
\hline "comfortable meeting with professors for academic help" & 3.9 & 3.9 & \\
\hline "professors inspire you to study engineering" & 3.6 & 3.6 & \\
\hline "meet with your professors for extra help" & 3.0 & 2.8 & \\
\hline "advisors in COE helpful" & 3.7 & 3.7 & \\
\hline "satisfied with COE job placement help" & 3.7 & 3.8 & \\
\hline "engineering students help each other to succeed" & 3.8 & 3.8 & \\
\hline "how often is lab work divided equally among lab groups" & 3.5 & 3.7 & \\
\hline "involved with student study groups" & 3.0 & 2.8 & \\
\hline NSSE question & $\begin{array}{c}\text { Mean } \\
\text { F }\end{array}$ & $\begin{array}{l}\text { Mean } \\
\text { M }\end{array}$ & Sig. \\
\hline "talked about career plans with a faculty member" (out of 4) & 2.26 & 2.04 & $*$ \\
\hline $\begin{array}{l}\text { "worked harder than you thought you could to meet an instruc- } \\
\text { tor's expectations" (out of } 4 \text { ) }\end{array}$ & 2.65 & 2.44 & $*$ \\
\hline $\begin{array}{l}\text { "worked with faculty members on activities other than course- } \\
\text { work" (out of 4) }\end{array}$ & 1.95 & 1.77 & $*$ \\
\hline
\end{tabular}

Female and male students responded with a high mean (3.8) to the question of how often "engineering students help each other to succeed." Notable gender differences in academic group work appeared with respect to lab groups and study groups. In response to "how often is lab work divided equally among lab groups", the mean value was slightly lower for female students (3.5) compared to male students (3.7). Specifically, 10.5\% of the female students answered "all the time" as compared to $17.8 \%$ of the male students, and $14.0 \%$ of the female students answered "rarely" as compared to $6.1 \%$ of the male students. More female students $(33.6 \%)$ were "involved with student study groups" compared to male students $(25.7 \%)$. The mean value was slightly higher for female students (3.0 vs. 2.8$)^{1}$.

The NSSE study shows statistically significant gender differences for Michigan Tech students in the following questions related to faculty members. About $35 \%$ the female students as compared to $24.0 \%$ percent of the male students responded "often" or "very often" to "talked about career plans with a faculty member". Twice as many female students $(21.2 \%)$ compared to male students (11.1\%) "worked harder than you thought you could to meet an instructor's standards or expectations". Finally, $63.4 \%$ of the female students reported having "worked with faculty 
members on activities other than coursework (committees, orientation, student life activities, etc.)" as compared to $49.9 \%$ of the male students ${ }^{18}$.

\section{IV.b. Internalization and Perceptions of Major and Career}

Student persistence is impacted by which outside influences affect them and how they react to these influences. We investigated the influences of student perceptions of engineering and computer science as a profession, how a career in computer science or engineering would impact the family-work-life balance, and the importance of selecting a career where the work would benefit society. Table 2 summarizes the results discussed here, presenting the data from the persistence survey and the PACE study for the questions related to internalization and perceptions of the major and career.

With respect to our survey, students were asked about their perceptions of the engineering or computer science professions depending on which career they had selected. Several questions focused on being able to obtain a job after graduation, and having that job be well-paying. When asked why they switched majors, two of the most important factors were that their new major had better job prospects (mean of 2.98) and better income potential (mean of 2.46). Female students ranked having better income potential as more important than did male students ${ }^{3}$. Previous research agrees, showing that students who persist in engineering considered job security more important when choosing a major than those who switched majors ${ }^{9}$.

In the PACE study, students were asked whether they "believe that engineers are well-paid" (with a scale of 1: strongly disagree -5 : strongly agree). Both men and women students agreed with this statement, with means of 4.3 and 4.5, respectively. Although the results are not statistically significant in this case, female students are putting more emphasis on income than male students. When asked whether they believe they "will have no problem finding a job with an engineering degree", men and women engineering students again agree with the statement, with means of 4.1 and 4.0 , respectively ${ }^{1}$.

Jackson found that students who switched out of engineering were less likely to agree that earning an engineering degree would allow them to have a high job and income potential ${ }^{9}$. In our study, students who persisted rank income potential (mean of 3.72) and good job opportunities (mean of 4.00) as key reasons that they did persist. For both of these factors, women students rated them as more important than did male students ${ }^{3}$. This result agrees with previous research, where it was shown that expected salary was an important predictor of persistence in engineering for women students, but not for men ${ }^{9}$.

Another group of questions in the PACE survey related to the career and overall life balance engineers have. When asked whether "engineering supports people who want to have children and continue working", the results were not significantly different by gender. However, males responded with a slightly higher mean (3.6) than females (3.4). Students were also asked whether they agree that "engineering supports a balance between work and family", and both men and women responded with a neutral mean of 3.2 ${ }^{1}$. Conversely, in 1993, students were asked how much time they anticipated taking off from work when they have children. The results showed that women expected to take more time off, however male students that persisted in engineering expected to take more time off than male students who switched majors? 9 
Table 2: Results of Three Surveys for Internalization and Perceptions of Major and Career

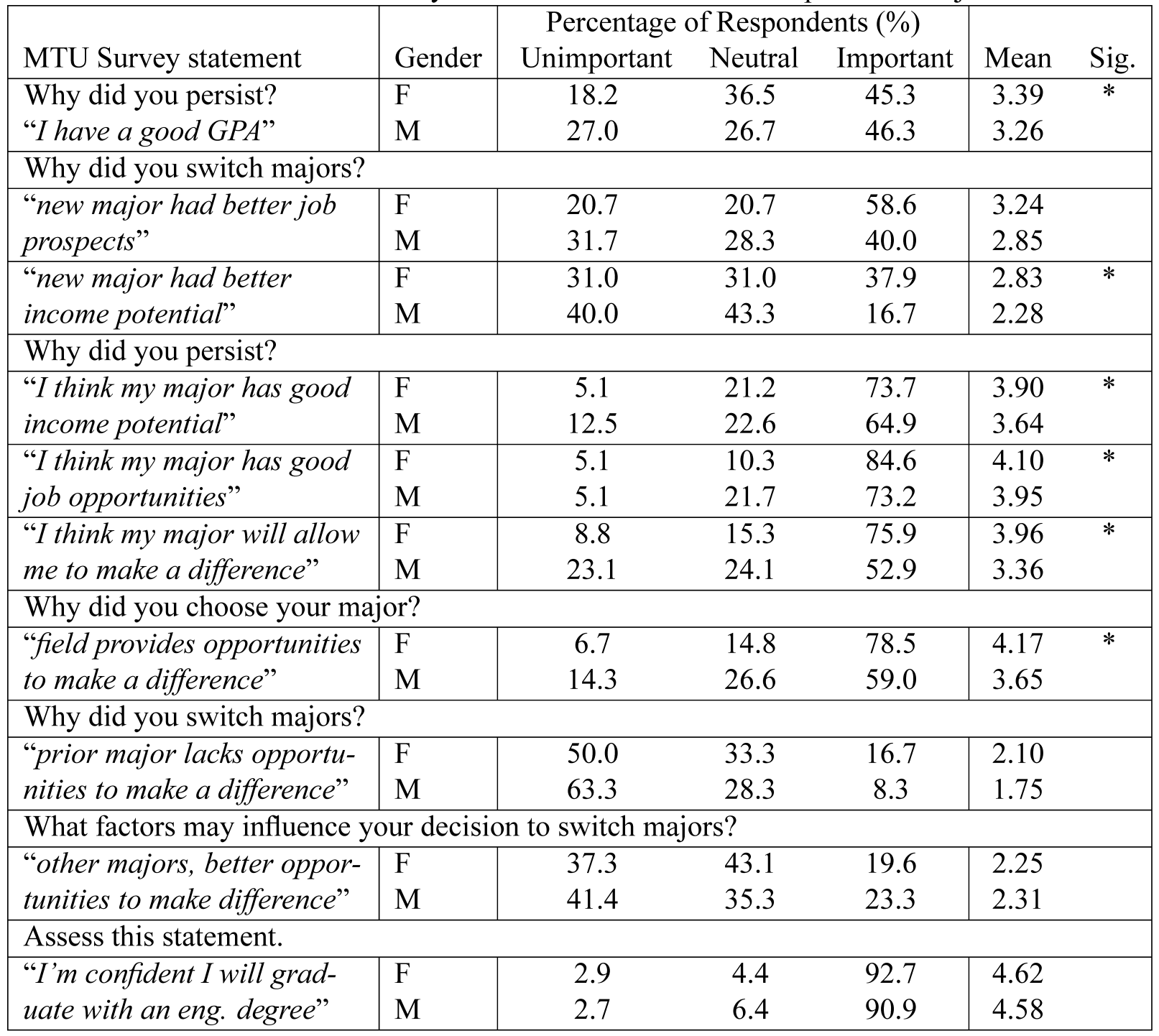

\begin{tabular}{|l|rc|}
\hline & \multicolumn{3}{|c|}{ Mean } & Mean \\
PACE question & $\mathrm{F}$ & $\mathrm{M}$ \\
\hline "believe that engineers are well-paid" & 4.5 & 4.3 \\
\hline "will have no problem finding a job with an eng. degree" & 4.0 & 4.1 \\
\hline "eng. supports people who want children and continue working" & 3.4 & 3.6 \\
\hline "engineering supports a balance between work and family" & 3.2 & 3.2 \\
\hline "engineers help to make the world a better place" & 4.5 & 4.5 \\
\hline "engineering is respected by other people" & 4.4 & 4.3 \\
\hline "society values the work engineers do" & 4.2 & 4.0 \\
\hline "it is my choice to study engineering" & 4.7 & 4.7 \\
\hline "intend to complete my engineering degree" & 4.8 & 4.8 \\
\hline "forecast time as engineer after graduating" & 4.0 & 4.5 \\
$*$
\end{tabular}


Students were asked about their perceptions of the impact engineers have on the world, and of how society views the engineering profession. In our study, we found that "having the opportunity to make a difference in the world" was an important factor both in choosing an initial major (mean of 3.82), and in persisting within engineering (mean of 3.55). In both of these questions, this factor had a significant difference between women and men. When students changed majors or were thinking about changing, "having an opportunity to make a difference" became a less important factor for both men and women, with a mean of 1.87 for those who did switch, and a mean of 2.31 considering a switch ${ }^{3}$. In the PACE study, when students were asked whether they agree that "engineers help to make the world a better place", both men and women responded with a high mean of 4.5. When asked whether they believe "engineering is respected by other people", these means dropped slightly to 4.4 for females and 4.3 for males. Students do believe that "society values the work engineers do", but the means were again slightly lower, with 4.2 for females and 4.0 for males ${ }^{1}$.

Prior research showed that those who persist in engineering view making a contribution to their field as more important than do those who switch majors ${ }^{9}$. Burtner verified this result when she found that those who persist in engineering majors view engineering as a respectable field and as having a positive impact in the world, while those who switched out of engineering agree less often with these statements ${ }^{5}$.

A student's own interest in engineering can be a large factor in persistence. In the PACE study, students were asked if "it was their choice to study engineering" (with a scale of 1: strongly disagree - 5: strongly agree). Both men and women students overwhelmingly agreed with this statement, with a mean of $4.7^{1}$. This result matched our survey, in that students report that they use their own personal judgment as the principle factor in making their decision to persist or not ${ }^{3}$. In a prior study, there was a statistically significant difference between the responses of students who persisted and those who switched majors when asked how much they enjoy engineering 5 . In another study, a loss of interest in engineering or science was reported as one of the key reasons for leaving these majors ${ }^{2}$.

Our survey shows that a majority of engineering students are "confident that they would graduate with an engineering degree", with a mean of $4.60^{3}$. Similarly in the PACE study, both men and women students strongly agreed that they "intend to complete their engineering degrees", with a mean of $4.8^{1}$.

As part of the PACE study, students were asked to, "forecast time as an engineer after graduating". Women $(9.6 \%)$ perceive that they will work as an engineer early in their career more than men (3.2\%). As time in the career progresses, the trend switches. More men $(67.3 \%)$ expect to have a $20+$ year career than women $(54.4 \%)^{1}$. This trend is similar to the findings of Ohland, et al where national data from both the NSSE and the MIDFIELD data were analyzed ${ }^{19}$.

\section{IV.c. Climate and Experiential Effects}

Table 3 summarizes the results discussed here, presenting the data from the persistence survey, the PACE study, and the NSSE study for the questions related to climate and experiential effects. One aspect of our persistence survey and the PACE survey was to determine how the campus climate and the engineering career climate affected student persistence. In our study, students were asked if departmental environment and diversity affected their decision to switch majors. Students, regardless of gender, stated that these factors did not affect their decision ${ }^{3}$. The PACE 
study asked students "if they had been singled out due to race, ethnicity and/or gender". Overwhelmingly, $96.7 \%$ of the students reported that they had not been singled out with respect to race/ethnicity. The percentage dropped when asked if they had been singled out due to gender. In this case, $87.4 \%$ overall (79.8\% for women) stated "no". When the students were asked if "faculty expressed gender stereotypes", the majority (79.2\%) of students responded negatively. However, the results were statistically significant with regards to gender differences with $90.9 \%$ of the men (70.1\% of the women) stating that they have not heard faculty express any gender stereotypes ${ }^{1}$.

Table 3: Results of Three Surveys for Climate and Experiential Effects

\begin{tabular}{|c|c|c|c|c|c|c|c|}
\hline \multirow[b]{2}{*}{ MTU Survey statement } & \multirow[b]{2}{*}{ Gender } & \multicolumn{4}{|c|}{ Percentage of Respondents (\%) } & \multirow[b]{2}{*}{ Mean } & \multirow[b]{2}{*}{ Sig. } \\
\hline & & Unimportant & Neutral & \multicolumn{2}{|c|}{ Important } & & \\
\hline \multicolumn{8}{|l|}{ Why did you switch majors? } \\
\hline \multirow{2}{*}{$\begin{array}{l}\text { "prior major lacked a } \\
\text { supportive environment" }\end{array}$} & $\mathrm{F}$ & 63.3 & 26.7 & \multicolumn{2}{|c|}{10.0} & \multicolumn{2}{|l|}{1.77} \\
\hline & M & 55.0 & 26.7 & \multicolumn{2}{|c|}{18.3} & \multicolumn{2}{|l|}{2.05} \\
\hline \multirow{2}{*}{$\begin{array}{l}\text { "prior major lacked } \\
\text { diversity" }\end{array}$} & $\mathrm{F}$ & 66.7 & 26.7 & \multicolumn{2}{|c|}{6.7} & \multicolumn{2}{|l|}{1.63} \\
\hline & M & 68.3 & 23.3 & \multicolumn{2}{|c|}{8.3} & \multicolumn{2}{|l|}{1.60} \\
\hline \multicolumn{8}{|l|}{ Assess this statement. } \\
\hline \multirow{2}{*}{$\begin{array}{l}\text { "I can succeed in eng. and } \\
\text { participate in other act." }\end{array}$} & $\mathrm{F}$ & 2.9 & 14.6 & \multirow{2}{*}{\multicolumn{2}{|c|}{$\begin{array}{l}82.5 \\
74.5 \\
\end{array}$}} & 4.18 & \multirow[t]{2}{*}{$*$} \\
\hline & M & 10.4 & 15.1 & & & 3.97 & \\
\hline \multirow{2}{*}{$\begin{array}{l}\text { "I can relate to the students } \\
\text { in my classes" }\end{array}$} & $\mathrm{F}$ & 2.9 & 14.6 & \multicolumn{2}{|c|}{82.5} & 4.10 & \multirow[t]{2}{*}{$*$} \\
\hline & $\mathrm{M}$ & 10.7 & 21.5 & \multicolumn{2}{|c|}{67.8} & 3.77 & \\
\hline \multirow{2}{*}{\multicolumn{4}{|c|}{ PACE question }} & \multicolumn{4}{|c|}{ \% Response,"Yes" } \\
\hline & & & & \multicolumn{2}{|c|}{$\mathrm{F}$} & $\mathrm{M}$ & \multirow[t]{2}{*}{ Sig. } \\
\hline \multicolumn{4}{|c|}{ "have you been singled out unfairly due to race or ethnicity" } & \multicolumn{2}{|c|}{0.8} & 1.4 & \\
\hline \multicolumn{4}{|c|}{ "have you been singled out unfairly due to gender" } & 14. & & 1.4 & $*$ \\
\hline "have heard faculty express & nder ster & types" & & 25. & & 6.8 & $*$ \\
\hline "participation in engineerin & tudent so & ieties" & & 32. & & 18.4 & $*$ \\
\hline "participation in summer re & arch" & & & 16. & & 5.9 & $*$ \\
\hline "participation in volunteer & & & & 55. & & 37.3 & $*$ \\
\hline NSSE question & & & & & $\begin{array}{c}\text { Mean } \\
\text { F }\end{array}$ & $\begin{array}{c}\text { Mean } \\
\text { M }\end{array}$ & Sig. \\
\hline $\begin{array}{l}\text { "attended an art exhibit, pl } \\
\text { mance" (out of } 4 \text { ) }\end{array}$ & dance, $n$ & sic, theater, ot & other pe & & 2.36 & 2.05 & $*$ \\
\hline $\begin{array}{l}\text { "participated in activities to } \\
\text { prayer, etc.)" (out of } 4 \text { ) }\end{array}$ & thance sp & ituality (worsh & , medita & & 2.25 & 1.83 & $*$ \\
\hline "relationships with other stu & nts" (out & f 7) & & & 6.04 & 5.68 & $*$ \\
\hline $\begin{array}{l}\text { "discuss ideas from your } r \\
\text { class" (out of } 4 \text { ) }\end{array}$ & dings or & asses with oth & rs outsic & & 2.91 & 2.62 & $*$ \\
\hline
\end{tabular}

Within the three studies, women reported more frequently than men that they could be successful students and participate in other activities. In our study, a significant difference between men and women occurred when they answered the question: "I can succeed in engineering/computer 
science and still participate in other activities" (82.5\% of women agreed compared to $74.5 \%$ of men $)^{3}$. The PACE study had similar results where several categories of activities showed significant differences in participation between men and women, e.g., "engineering student societies" (32.8\% women, 18.4\% men), "summer research" (16.4\% women, 5.9\% men), and "volunteer work" (55.5\% women, $37.3 \%$ men $)^{1}$. In the NSSE study, similar questions about students' level of involvement outside of the classroom were asked. A significant gender difference was found in the responses, where $35.7 \%$ of women "attended an art exhibit, play, dance, music, theater, or other performance", compared to only $22.8 \%$ of men. Similarly, $34.5 \%$ of female students "participated in activities to enhance their spirituality (worship, meditation, prayer, etc.)", while $22.3 \%$ of men did the same ${ }^{18}$.

Another important aspect of climate is how a student relates to the people around them, both other students and faculty members. In the persistence study, there was a significant gender difference where $82.5 \%$ of women agreed that "they can relate to other students in their classes", while $67.8 \%$ of men agreed ${ }^{3}$. These results match a similar question in the NSSE study, where $81.2 \%$ of female students rated their "relationships with other students" highly, compared to $62.1 \%$ of male students. On the other hand, when they were asked "how often they discussed ideas from their readings or classes with others outside of class (students, family members, co-workers, etc.)", a slightly larger number of female students (54.4\%) reported that they do, compared to $51.7 \%$ of male students ${ }^{18}$.

\section{Conclusions}

In this paper, three studies were analyzed and compared. The first study was a small-scale, single institution survey focused on persistence. The multi-institutional PACE study looked at climate in engineering schools with an emphasis on factors that affect persistence. The NSSE study measured student engagement in all majors at a national level. Our analysis of the data from Michigan Tech revealed agreement among the three surveys on topics related to persistence.

We found significant gender differences were not prevalent, but when they occurred, they were consistently found in multiple instruments. Our analysis showed that when compared to men, women use a wider variety of resources (campus and personal) and they frequently discuss course topics with others outside of class, but they find study centers to be less useful. Improvements to and awareness of engineering learning centers and other resources may create a positive environment and increase the number of women students finding them useful. Women are less confident about succeeding in engineering courses, but their GPAs are similar to men. In terms of perceptions of career and work-life balance, the men and women did not have significant differences. However, in the small-scale survey when asked about the reasons for choosing and persisting in a major, the opportunity to make a difference in the world was rated as a significantly more important factor by women.

The small-scale and the NSSE surveys found that women state they can be successful students in engineering while also participating in other activities (such as attending performances, enhancing spirituality, etc.). In both studies, more women said they can relate to other students and work with faculty members on activities other than coursework. The PACE study found an overwhelming number of students did not experience gender stereotypes, but women report more 
often than the men of being unfairly singled out due to gender and that faculty express gender stereotypes.

The overall positive experiences found in the three university studies contrast with Singh and Fouad's study of persistence in an engineering career. Their results show that women leave the engineering workforce due to low career satisfaction, conflicting work demands, and dissatisfaction with the climate ${ }^{6}$. This negative workplace environment perception may influence high school and beginning university, female students to not choose Eng\&CS fields or not persist in them. Although climate improvement efforts are underway, we recommend that these efforts continue within and extend to all organizations.

In future work, we will expand our analysis beyond gender differences to investigate differences based on year and primary major. We will extend our comparison to the national PACE and NSSE results. Additionally, we will look at how departmental gender composition of the faculty and students impacted the survey responses.

\section{References}

1. Brainard, S.G., Carlin, L., "A six-year longitudinal study of undergraduate women in engineering and science”. Journal of Engineering Education, 1998, pp. 369-375.

2. Brainard, S.G., Metz, S.S., Litzler, E., Jaros, S.L., "Project to Assess Climate in Engineering (PACE): Final Report", Center for Workforce Development, University of Washington, Seattle, WA, June, 009.

3. Bunker, K.J., Rebb, R.R., Brown, L.E., Hein, G.L., Onder, N., "Why do Women Engineering and Computer Science Undergraduates Persist in their Major?". Proceedings of the Women in Engineering ProActive Network (WEPAN) Annual Conference, 2011.

4. Bureau of Labor Statistics. "Occupational Outlook Handbook, 2010-11 edition”. Available at http://www.bls.gov/oco/, accessed January 6, 2012.

5. Burtner, J. " Critical-to-quality factors associated with engineering student persistence: the influence of freshman attitudes". Proceedings of the $34^{\text {th }}$ ASEE/IEEE Frontiers in Education Conference, CD-ROM, Session F2E, 2004.

6. Fouad, N.A., Singh, R., "Stemming the Tide: Why Women Leave Engineering,' Full Report to NSF. 2011. Available at http://www.studyofwork.com/2011/10/stemming-the-tide-women-engineers-report/, accessed January 6, 2012.

7. Hartman, H., Hartman, M., “Leaving Engineering: Lessons from Rowan University’s College of Engineering”. Journal of Engineering Education, January 2006, pp. 49- 61.

8. Ivins, J., von Konsy, B.R., Cooper, D., Robey, M., "Software Engineers and Engineering: A Survey of Undergraduate Preconceptions". 36th ASEE/IEEE Frontiers in Education Conference, San Diego, CA, 2006.

9. Jackson, L.A., Gradener, P.D., Sullivan, L.A., Engineering persistence: past, present, and future factors and gender differences. Research in Higher Education, 1993, Vol. 26, pp. 227-246.

10. Katz, S., Allbritton, D., Aronis, J., Wilson, C., Soffa, M.L., "Gender, Achievement, and Persistence in an Undergraduate Computer Science Program". The DATA BASE for Advances in Information Systems, Fall 2006, Vol. 37, No. 4.

11. Light, J., Korte, R., Yasuhara, K., and Kilgore. D. Exploring the relationships among performance on engineering tasks, confidence, gender and first year persistence. American Society for Engineering Education (ASEE) Conference, 2007, AC2007-1515.

12. Litzler, E. \& Young, J. "Understanding the Risk of Attrition in Undergraduate Engineering: Results from the Project to Assess Climate in Engineering." Journal of Engineering Education, to appear, 2012. 
13. McCain, J., Fleming, L., Williams, D., Engerman, K., "The Role of 'Doggedness' in the Completion of an Undergraduate Degree in Engineering". American Society for Engineering Education (ASEE) Conference, 2007.

14. Mendez, G., Buskirk, T.D., Lohr, S., Haag, S. "Factors Associated with Persistence in Science and Engineering Majors: An Exploratory Study using Classification Trees and Random Forests". Journal of Engineering Education, January 2008.

15. Morozov, A., Kilgore, D., Yasuhara, K., Atman, C. Same course, different outcomes? Variations in confidence, experience, and preparation in engineering design. American Society for Engineering Education (ASEE) Conference, 2008, AC2008-768.

16. National Center for Educational Statistics. "Digest of Education Statistics, 2010". Available at: http://nces.ed.gov/programs/digest/d10/, accessed January 6, 2012.

17. National Science Foundation, National Center for Science and Engineering Statistics. "Survey of Earned Doctorates: S\&E Degrees, Detailed Statistical Tables" Available at: http://www.nsf.gov/statistics/nsf11316/, accessed January 6, 2012.

18. National Survey of Student Engagement. "Assessment for improvement: Tracking student engagement over time - Annual Results 2009". Bloomington, IN: Indiana University Center for Postsecondary Research. Available at: www.nsse.iub.org, accessed January 6, 2012.

19. Ohland, M.W., Sheppard, S.D., Lichtenstein, G., Eris, O., Chachra, D., Layton, R., "Persistence, Engagement, and Migration in Engineering Programs". Journal of Engineering Education, July 2008, pp. 259-278.

20. PACE website, http://depts.washington.edu/paceteam/, accessed January 6, 2012.

21. Pierrakos, O., Beam, T.K., Constanz, J., Johri, A., Anderson, R., "On the Development of a Professional Identity: Engineering Persisters vs Engineering Switchers". 39th ASEE/IEEE Frontiers in Education Conference, San Antonio, TX, 2009.

22. Wyer, M., "Intending to Stay: Images of Scientists, Attitudes toward Women, and Gender as Influences on Persistence among Science and Engineering Majors". Journal of Women and Minorities in Science and Engineering, 2003, Vol. 9, Issue 1, pp. 1-16. 